\title{
A COMERCIALIZAÇÃO DO GUARANÁ PELOS CAMPONESES NA COMUNIDADE DIVINO ESPÍRITO SANTO DO CASTANHAL (BARREIRINHA/AM)
}

\section{The commercialization of guaraná by the camponeses in the Divine Spirit Santo Community From Castanhal (Barreirinha/AM)}

\author{
Sanae Ferreira de Souza \\ Graduanda no curso de Geografia Bacharelado \\ Universidade Federal do Amazonas-UFAM \\ sanae.ferreiragen2@gmail.com \\ Ana Claúdia Narbaes de Carvalho \\ Mestranda em Geografia - Programa de Pós-Graduação em Geografia \\ Universidade Federal do Amazonas-UFAM \\ claudianarbaes@hotmail.com \\ Manuel de Jesus Masulo da Cruz \\ Prof. Doutor em Geografia do Departamento de Geografia \\ Universidade Federal do Amazonas-UFAM \\ masulo@bol.com.br
}

\begin{abstract}
RESUMO: Este trabalho analisa a comercialização e a produção do guaraná pelos camponeses da comunidade Divino Espírito Santo do Castanhal Barreirinha/AM. O objetivo do trabalho surgiu mediante a uma comunidade pouco conhecida, que os camponeses estão desenvolvendo a prática do cultivo, que serve para comercialização, que logo extraem a renda que é essencial para permanecerem produzido. Para o desenvolvimento da pesquisa, foi realizado trabalho de campo no ano de 2015, foi feito entrevistas com os camponeses, perguntas semiestruturadas, câmera fotográficas e caderno de campo como principal elemento da pesquisa. A maioria dos camponeses realizam o cultivo do guaraná distantes de suas residências, outros preferem trabalhar com a mandioca, que se torna a principal base econômica dos camponeses. Na comunidade Divino Espírito Santo do Castanhal a produção do guaraná é comercializado para o consórcio sateré-mawé, que está territorializado na cidade de Parintins.
\end{abstract}

Palavras-chave: Produção do guaraná; camponês; unidade de produção; mercadoria; comercialização.

ABSTRACT: This work analyzes the commercialization and production of guaraná by the peasants of the Divine Espírito Santo community of Castanhal Barreirinha / AM. The objective of the work came about through a little-known community, which the peasants are developing the practice of cultivation, which serves for commercialization, which soon extract the income that is essential to remain produced. For the development of the research, fieldwork was carried out in the year 2015, interviews with peasants, semi-structured questions, photographic camera and field book were made as the main element of the research. Most peasants cultivate guaraná far from their homes, others prefer to work with cassava, which becomes the main economic base of peasants. In the Divine Espírito Santo community of Castanhal the production of guaraná is commercialized for the Sateré-Mawe consortium, which is territorialized in the city of Parintins.

Key-Words: Guarana production; farmer; Production unit; merchandise; commercialization. 
A COMERCIALIZAÇÃO DO GUARANÁ PELOS

CAMPONESES NA COMUNIDADE DIVINO

ESPÍRITO SANTO DO CASTANHAL

(BARREIRINHA/AM).

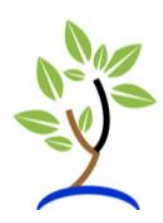

\section{INTRODUÇÃO}

Algumas comunidades do estado do Amazonas estão se inserindo com as práticas de cultivo do guaraná (Paullinia cupana). A Comunidade Divino Espírito Santo do Castanhal vem se destacando no cultivo do Guaraná, no qual acontece às transformações socioeconômicas a troca de mercadoria por dinheiro e visa versa. Neste sentido, o guaranazeiro vem se tornando uma das mais importantes atividades econômica da comunidade, juntamente com outras produções agrícolas, no qual se destaca a farinha de mandioca, que ora é utilizado para o consumo familiar e do excedente comercializado, ambos necessário para a reprodução da família camponesa.

No entanto, a comercialização do guaraná é realizada por meio do Consórcio SateréMawé (CSM), que está territorializado na cidade de Parintins, o consórcio compra a matéria prima, ou seja, depende da mesma para continuar se reproduzindo, da mesma maneira que o camponês depende do consórcio para comercializar sua produção.

Para os camponeses a renda da mercadoria é essencial para sua recriação na unidade de produção, somente assim, são reconhecidos que são trabalhadores, que possuem uma organização social de trabalho em sua unidade, que uma vez territorializado demostram que possuem afinidade com a terra, no qual tiram sua renda por meio dela, pois precisam comprar outras mercadorias que não contém em sua unidade.

Portanto, o objetivo da pesquisa é analisar como os camponeses desenvolvem as práticas de cultivo do guaraná, se realizam trabalho mútuo, se existe trabalho acessório e dentre outras características da agricultura camponesa, pois todo o trabalho que é exercido em sua unidade de produção tem uma finalidade, resta-nos compreender quais são estas.

A maioria dos camponeses que residem na comunidade não são indígenas, alguns são oriundos dos municípios de Nova Olinda do Norte, Parintins, Barreirinha e de algumas comunidades próximas. Mesmo não sendo de origem indígenas, trabalham no cultivo da mandioca, guaraná e dentre outros essenciais para sua reprodução, e essa tradição é passada de pai para filho. "Desde pequena a criança aprende a conhecer tudo que existe a seu redor seguindo os pais e irmãos mais velhos. Aprende a arte de andar de canoa e orientar-se pelos caminhos do mato" (UGGÉ, 1993, p.21).

A comunidade Divino Espírito Santo está localizada no município de Barreirinha (AM), no rio Andirá, sendo, portanto, constituída aproximadamente por 40 famílias, tendo como sua principal atividade econômica às roças de mandioca e o guaraná, sendo que a comunidade está em área de terra firme. 
A COMERCIALIZAÇÃO DO GUARANÁ PELOS

CAMPONESES NA COMUNIDADE DIVINO

ESPÍRITO SANTO DO CASTANHAL

(BARREIRINHA/AM).

\section{MATERIAIS E MÉTODOS}

Para este trabalho foram realizadas pesquisas de campo no ano de 2015 na comunidade Divino Espírito Santo, realizou-se entrevistas semiestruturadas. A maioria das entrevistas eram feitas nos roçados (locais de produção), no qual o camponês mostrava as áreas de cultivos, havendo a necessidade de mapear as unidades de produções, mediante a autorização dos camponeses, utilizando anotações em caderno e aplicação de questionário como principal elemento.

A seguir mapa de localização da comunidade Divino Espírito Santo do Castanhal:

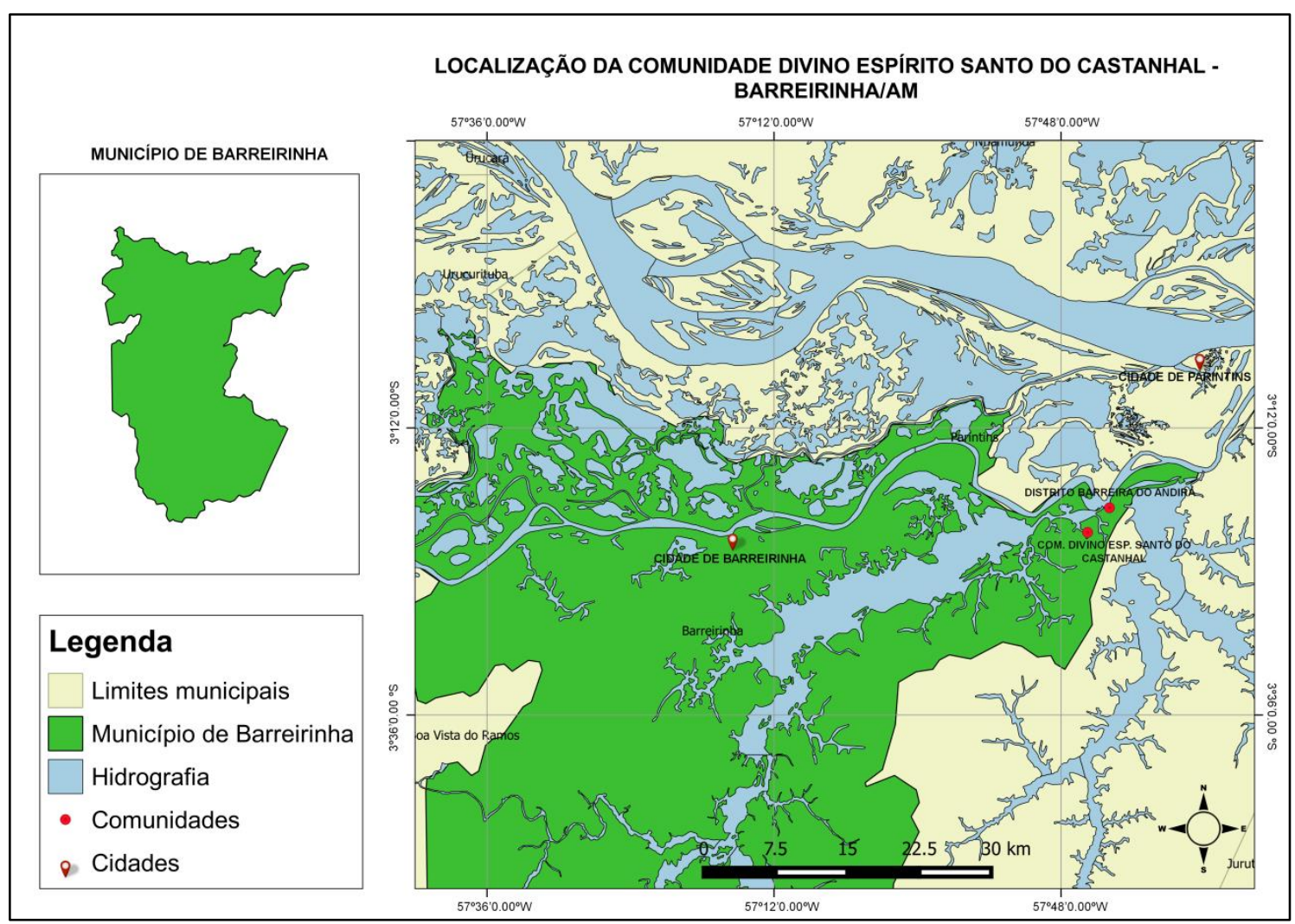

FIGURA- 1: Comunidade Divino Espírito Santo do Castanhal.

Fonte: Base cartográfica IBGE, 2010.Org: Arenilton Serrão, 2017.

\section{A IMPORTÂNCIA DA COMERCIALIZAÇÃO DO GUARANÁ PARA OS CAMPONESES}

A maneira como cada camponês se estabelece em sua unidade é simples, ou seja, estão sempre se reproduzindo, por meio do trabalho com a terra, no qual serve para satisfazer a necessidade da família, o que eles cultivam servem em primeiro lugar para sua subsistência e em segundo para a comercialização. 
A COMERCIALIZAÇÃO DO GUARANÁ PELOS

CAMPONESES NA COMUNIDADE DIVINO

ESPÍRITO SANTO DO CASTANHAL

(BARREIRINHA/AM).

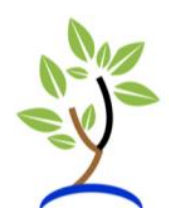

A comunidade Divino Espírito Santo do Castanhal está localizada em área de terra firme, no qual o trabalho com a terra é constante para o cultivo, algumas comunidades que estão localizadas em área de várzeas, que em época de ano a principal atividade é a pesca, alguns desenvolvem estratégicas de construir balcões, que geralmente se cultiva (cebolinha, cheiro-verde, pimenta, plantas medicinais e dentre outros), porém não é somente em área de várzea que essa atividade torna explícita, pois é uma domesticações trazidas pelos primeiros povos, que para Martins (2014):

\begin{abstract}
A história da domesticação de plantas no Brasil começa com os primeiros povos que ocuparam a terra, considera-se que a Amazônia poderia ter de 4 a 5 milhões de habitantes que cultivavam ou manejavam 138 espécies no ano de 1492 (MARTINS, 2014, p.3).
\end{abstract}

A domesticação das plantas é essencial, pois só eles carregam em si a tradição de cultivar, os camponeses da comunidade cultivam (cebolinha, cheiro-verde, plantas medicinais), que servi somente para o consumo. Nesse sentido, a terra é o principal elemento na vida dos camponeses, como argumenta Moura (1988):

Com a terra e o meio de produção principal para que exista a relação entre produção e consumo, entre morada e trabalho, sua herança desempenha um papel estratégico na existência camponesa: é um dos fundamentos sobre os quais se apoia a produção social do campesinato (MOURA, 1988, p. 28).

Que uma vez estabelecidos na unidade de produção são capazes de se reproduzir por meio de suas estratégicas, que são mediadas a partir das necessidades da família camponesas. Na comunidade o que mais é cultivado é a mandioca e o guaraná, no caso do guaraná, se tornou umas de sua principal base econômica, gerando renda para os camponeses, para desse modo comprar outras mercadorias que não existem em sua unidade. Pois a lógica é simples, a meta não é acumular lucro, e sim ter dinheiro para comprar mais mercadorias, quanto mais for sua renda adquirida da comercialização de sua mercadoria, mais desenvolverá a compra de outras mercadorias. A importância de comercializar o guaraná está diretamente ligada ao Consórcio Sateré-Mawé (CSM), pois é uma alternativa para que os camponeses possam vender sua produção, certo que eles somente comercializam o guaraná para o consórcio, tendo como alternativa de renda para continuarem a se reproduzir.

Portanto, cada produto que sai da unidade de produção camponesa para a comercialização, complementa sua renda, cada unidade cultiva produtos diferentes, uns vão ter bastante relevância no mercado, outros não, desse modo, é explicito entender que o guaraná (Paullinia cupana Kunth) e a mandioca (Manihot esculenta Crantz) é bastante comercializados, diferente da goiba (Psidium guajava $L$ ), que não tem muita relevância na comercialização para os camponeses da comunidade. Desse modo, produção é imediatamente consumo, conforme Marx (1982):

A produção é mediadora do consumo, cujos materiais cria e sem os quais não teriam objeto. Mas o consumo é também mediador da produção ao criar para os produtos o sujeito, para o qual são produtos. O produto recebe seu acabamento final no consumo, uma estrada de ferro em que não se viaja e que e que, por conseguinte, não se gasta, não se consome, não é mais que uma estrada de ferro dynamei, e não é efetiva. Sem produção não há consumo, mas sem consumo tampouco há produção. O consumo produz de uma dupla maneira a produção (MARX, 1982, p.8).

REVISTA GEONORTE, V.9, N.31, p.137-153, 2018.

(ISSN 2237 - 1419)

Edição especial 10 Anos do Programa de Pós-graduação em Geografia PPEOG - UFAM 140 DOI: 10.21170/geonorte.2018.V.9.N.31.137.153 
A COMERCIALIZAÇÃO DO GUARANÁ PELOS

CAMPONESES NA COMUNIDADE DIVINO

ESPÍRITO SANTO DO CASTANHAL

(BARREIRINHA/AM).

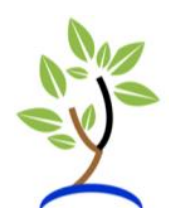

Os camponeses comercializam para os atravessadores, no qual atribui outro valor, ou seja, a mercadoria é valiosa, pois é comercializado o dobro pelo qual foi vendido pelo camponês, nesse sentido, o camponês é uma classe social que faz parte do capitalismo "isto quer dizer que parte-se também, do pressuposto de que o camponês não é um sujeito social de fora do capitalismo, mas sim, um sujeito social de dentro do capitalismo", (OLIVEIRA, 2007, p. 131). O camponês como uma classe social se reproduz em duas maneiras de comercializar, ou ele vende para o capital (atravessador, cooperativas, consórcio e dentre outros), que se reproduz por meio da mercadoria obtendo lucro, ou para o próprio consumidor final, que não precisa se reproduzir para obter lucro.

Para se ter a comercialização, os camponeses estabelecem determinadas organizações de trabalhos, ou seja, cada família camponesa possui uma especialidade em suas áreas de cultivo, portanto desenvolvem diferentes aspectos na produção, no qual vai resultar na materialização do seu produto, que ora serve para sua subsistência ora para a comercialização, que tem como finalidade o consumo.

$\mathrm{Na}$ unidade de camponesa o que prevalece é Mercadoria - Dinheiro - Mercadoria (MD-M), no qual conseguem adquirir renda e comprar outras mercadorias, sendo assim a comercialização é essencial para seu modo de vida, a mercadoria que é comercializada está o trabalho do camponês que foi obtido pelo pela força de trabalho, que para Araújo (2014):

Preço da força de trabalho é apenas a expressão do valor dessa mercadoria em dinheiro. No entanto o verdadeiro preço de mercado da força de trabalho não necessariamente coincide com o seu valor, podendo situar-se acima (ou frequentemente) abaixo dele (ARAÚJO, 2014, p.10).

Desse modo a família camponesa se organiza para trabalhar no guaraná, geralmente os homens são responsáveis por fazer a colheita, e para isso saem cedo de suas residências para ir até o local de cultivo, sendo assim inicia-se a colheita, tendo como a jornada de trabalho de 5 horas é o tempo que leva para preencher aproximadamente 5 sacas de guaraná, no qual retornam para sua residência, o transporte que é realizado do local do cultivo para a residência é em triciclos, que suporta aproximadamente 6 sacas de guaraná, como mencionado são os homens que ficam responsáveis pela colheita, e raramente as mulheres que fazem o acompanhamento, o trabalho das mulheres são na própria unidade de produção, ou seja, onde é realizado a preparação do guaraná, elas geralmente ajudam na torração.

No final de toda a materialização, a matéria prima é logo comercializada para o consórcio dos produtores Sateré- Mawé, uma unidade de beneficiamento de Parintins, no qual compram essa mercadoria, tornando-se uma mercadoria valiosa, pois por meio dela, pode-se reproduzir e torna-la a ter outros valores, nesse sentido argumenta Oliveira (2007).

O desenvolvimento do capitalismo é produto de um processo contraditório de reprodução capitalista ampliada do capital. Ou seja, o modo capitalista de produção não está circunscrito apenas a reprodução imediata, mas também à circulação de mercadoria, portanto inclui também a troca de mercadorias por dinheiro e, obviamente de dinheiro por mercadoria (OLIVEIRA, 2007, p. 20).

REVISTA GEONORTE, V.9, N.31, p.137-153, 2018.

(ISSN 2237 - 1419)

Edição especial 10 Anos do Programa de Pós-graduação em Geografia PPEOG - UFAM 141 DOI: 10.21170/geonorte.2018.V.9.N.31.137.153 
A COMERCIALIZAÇÃO DO GUARANÁ PELOS

CAMPONESES NA COMUNIDADE DIVINO

ESPÍRITO SANTO DO CASTANHAL

(BARREIRINHA/AM).

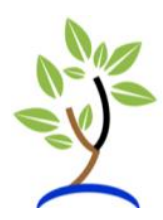

Para o camponês o que interessa é comercializar sua produção para ter renda e adquirir outras mercadorias, como mencionado o camponês trabalha primeiramente para satisfazer sua necessidade, pois é por meio do trabalho com a terra que reproduz o seu modo de vida. O cultivo do guaraná é essencial para a reprodução camponesa, pois é dessa forma que são reconhecidos que são trabalhadores, na sua unidade possuem uma organização de trabalho,

A mandioca e o guaraná são bastante cultivados pelos camponeses, tornando-se o elemento principal do sistema de cultivo, o trabalho com a mandioca sempre foi uma alternativa de comercialização e o trabalho com o guaraná é o segundo elemento do sistema de cultivo mais comercializado, no qual foram desenvolvendo as práticas de cultivo do guaraná, dos entrevistados afirmaram que não tinha conhecimento sobre como cultivar o guaraná, muitos deles encontravam plantado na mata o que dificultava o acesso até o plantio do guaraná, sendo assim retiravam as mudas e cultivavam nos roçados, às vezes encontravam dificuldade, pois a maioria das mudas não brotava, no qual tiveram perdas na produção.

O Instituto de Desenvolvimento Agropecuário e Florestal Sustentável do Estado do Amazonas (IDAM) participou das técnicas de cultivo junto com os camponeses, no qual aprenderam as práticas de cultivo. O conhecimento é essencial, no qual é uma forma de saber e de trabalhar com a natureza, o camponês está adaptado a trabalhar conforme seu estilo de vida, ora pescam, ora cultivam, sendo que esses são fundamentos para sua reprodução, assim como realizam a comercialização da matéria-prima, realizam a compra de mercadorias, que para eles são essenciais. A maneira como manifestam a sua vida por meio da (necessidade, pesca, caça, costumes e dentre outros), reflete o que eles realmente são, como mencionado o trabalho geralmente é realizado por toda família, por isso, desde criança os pais ensinam os saberes tradicionais, que são passado de pai para filhos, seja no (cultivo, pesca, criação).

A maneira como os camponeses desenvolvem o cultivo do guaraná é por meio de sementeiras, possuindo tamanho apropriado, de $80 \times 90 \mathrm{~cm}$, que demora aproximadamente 40 dias, depois é colocado em saquinhos de plástico que demora aproximadamente 9 meses para ser retirada e colocada nas covas, como afirma Pereira (2007):

\begin{abstract}
Para uma boa produção de folhas exige solos ricos em matéria orgânica. A sua propagação ocorre tanto por semente quanto por estaquia, mas é grande produtora de sementes, a produção de mudas na atividade agrícola se constitui um fator importante pois a partir daí pode depender toda resposta da planta em relação aos seus atributos (PEREIRA, 2007, p. 85).
\end{abstract}

A seguir imagem de processo de cultivo do guaraná pelo camponês: 
A COMERCIALIZAÇÃO DO GUARANÁ PELOS CAMPONESES NA COMUNIDADE DIVINO ESPÍRITO SANTO DO CASTANHAL (BARREIRINHA/AM).
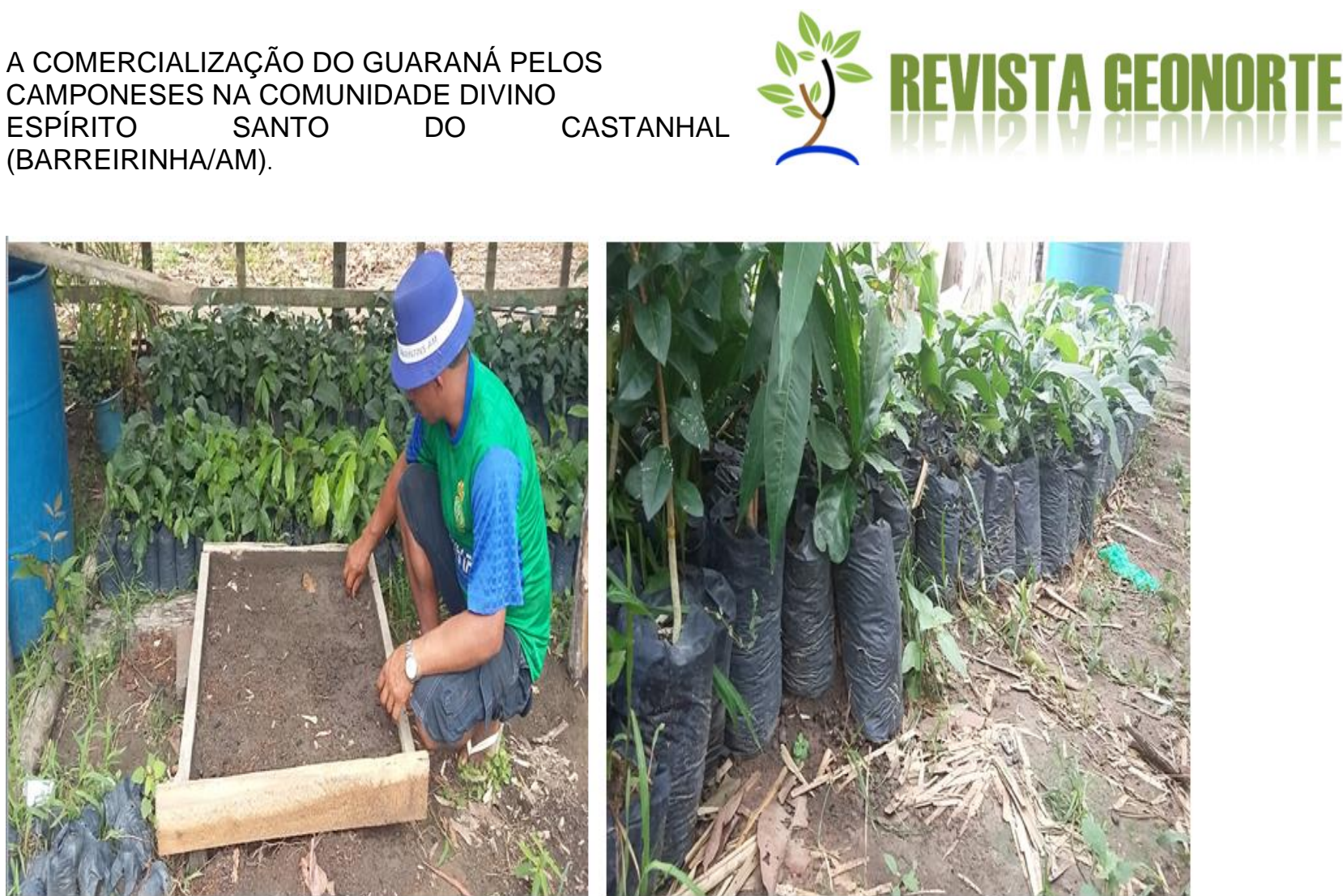

FIGURA 2 - Processo de cultivo do guaraná.

Fonte: Trabalho de campo (22/12/2015).

Quando se tem a safra do guaraná no mês de dezembro, é comercializado para o consócio por $R \$ 20,00$ a 10,00 kg, com a comercialização do guaraná já tiveram uma renda de $\mathrm{R} \$ 5.000$, no qual foi utilizado para comprar outras mercadorias que não necessariamente tenha em sua unidade de produção, como os camponeses estão começando a desenvolver as práticas de cultivo sua renda ainda é considerada pouca, para Tricald (2012), argumenta que:

Os entrevistados reconhecem nos Sateré-Maué a origem do guaraná que eles plantam que consomem, o que aponta de certa forma, para origem indígena do seu conhecimento. Assim, eles formaram durante muitos anos os seus plantios de guaraná apenas com mudas nativas coletadas na floresta, à imagem dos Sateré- Maué, por isso, foram também chamados de produtores extrativistas (TRICALD et al., 2012, p. 37).

\section{A PRODUÇÃO DO GUARANÁ NA COMUNIDADE DIVINO ESPÍRITO SANTO DO CASTANHAL- BARREIRINHA/AM.}

Com o crescimento do mercado de guaraná, que é considerado essencial para indústrias de refrigerante, algumas regiões desenvolve a prática de cultivo, como é o caso da região norte, mais especificamente no Estado do Amazonas no qual o guaraná (Paullinia cupana), é uma planta propriamente nativa da região. Entretanto, muitas comunidades desenvolvem a prática de cultivo, como é o caso da comunidade Divino Espírito Santo do Castanhal, localizada no munícipio de Barreirinha-AM, no qual a produção tem uma forte influência no modo de vida dos camponeses e principalmente para o capital monopolista. 
A COMERCIALIZAÇÃO DO GUARANÁ PELOS

CAMPONESES NA COMUNIDADE DIVINO

ESPÍRITO SANTO DO CASTANHAL

(BARREIRINHA/AM).

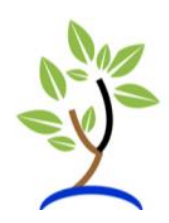

A prática pelo cultivo se tornou um dos principais focos dos camponeses, no qual começaram a cultivar no ano de 2001, a partir daí muitos camponeses se dedicaram ao cultivo, outros somente trabalham com o cultivo da mandioca, que é uma das principais bases econômicas. Alguns deles ressaltaram que não trabalham com o guaraná por ser um produto que precisa de ajuda familiar, e não tem quem os ajude a trabalhar, e preferem cultivar a mandioca, que tanto serve para sua subsistência como para a comercialização, pois em algumas unidades só existe duas pessoas, que trabalham para comercialização, embora em outras unidades ainda exista a ajuda mútua, ou seja, varia a maneira como cada camponês trabalha, alguns trabalham com menos pessoas, outros participam da ajuda mútua e outros pagam, ou seja, por meio do trabalho acessório. Como mencionado uns trabalham com menos pessoas, ou seja, o pai e a mãe, que quando vendem a mercadoria, que geralmente não é muito, recebem pouca renda, e adquirem poucas mercadorias. Já outros pagam para outros camponeses, com intuito de adquirir mais renda para comprar mais mercadorias.

O trabalho na unidade de produção começa com o guaraná, pois é aí que está o inicio de todo o processo (Produção, Distribuição, Circulação, Consumidor final), na produção envolve dois espaços, que é o rural e o urbano, ou seja, uma parte da produção do guaraná é realizada na própria unidade do camponês, sendo a matériaprima, tendo desse modo o trabalho abstrato, pois foi utilizado todo um dispêndio da força de trabalho, e é por isso que possuem uma organização de trabalho, para desse modo se ter a mercadoria materializada, pois as mercadorias vêm ao mundo em forma de valores de uso e com isso se tem os valores de troca, nesse sentido, o guaraná torna-se valores te troca comercializado para Parintins, no caso da distribuição e circulação das mercadorias, o transporte é essencial nesse processo, no qual é por via fluvial, para Bilacrês (2013):

\begin{abstract}
A questão dos transportes não se limita aos termos da logística ou das técnicas/tecnologia. A questão é política, ou melhor, no contexto da economia política dos territórios, isto é, a circulação como processo geográfico, pois envolve questões sociais e naturais; envolve apropriações, consumo, monopólio de infraestrutura, força de trabalho. Visto que é na circulação que se cria valor, pelo consumo de valor de uso transformado em valor de troca, o processo em que chega ao consumidor, ou um prolongamento do processo de produção, um aumento na escala da produção (BILLACRÊS, 2013, p. 114).
\end{abstract}

Quando a mercadoria precisa ser levada para Parintins, os camponeses precisam se deslocar da própria comunidade para o Distrito de Barreira do Andirá, no qual os camponeses também trabalham com o cultivo do guaraná, os agentes sociais pertencentes ao consócio são responsáveis pelo busca da mercadoria no Distrito, pois a localização onde fica a comunidade é de difícil acesso, principalmente de barcos, ou seja, os camponeses utilizam rabetas (canoa de porte pequeno, geralmente motor 15) para transportar a mercadoria. O Distrito Barreira do Andirá é um dos lugares em que os camponeses já vinham desenvolvendo o guaraná, ou seja, já eram associados pelo consocio Sateré-mawé, mesmo antes dos camponeses da comunidade Divino Espirito Santo começarem a se dedicar ao cultivo do guaraná. 


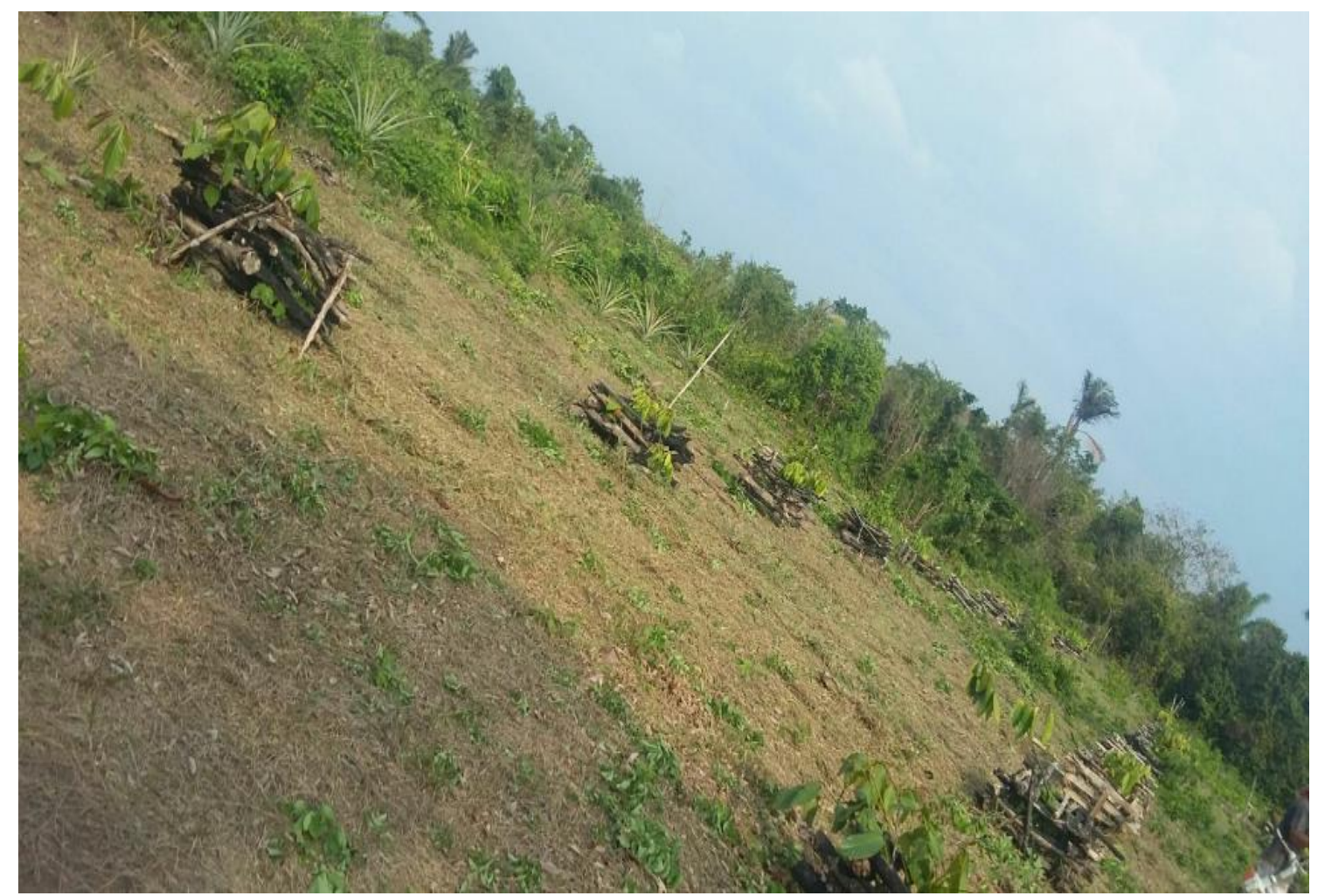

FIGURA 3 - Roçados de guaraná, cultivados em forma de linha na comunidade Divino Espírito Santo do Castanhal- Barreirinha/AM.

Fonte: Trabalho de campo (22/12/2015).

O camponês é uma base indispensável para reprodução social, no qual desenvolvem seu trabalho por meio da terra, constituem o seu modo de vida, que é por meio desta que desenvolvem as práticas de cultivos, que ora serve para sua subsistência e ora para comercialização. Nesse sentido vale ressaltar o conceito de camponês que Shanin (1980):

Um camponês não é uma palavra vazia a refletir os preconceitos do populus, as frivoridades linguísticas dos intelectuais ou, ainda, conspirações de adeptos de uma ideologia, embora às vezes isso possa ser verdadeiro. Se revogado esse conceito (ainda?) não pode ser facilmente ser substituído por outro de natureza semelhante. Ele tem, assim como conceitos de capitalismo, proletariado e, é claro, modo de produção, potenciais de reificação, isto é, pode ser enganoso, assim como pode ser usado para enganar, especialmente quando utilizado de maneira ingênua. Tem se dito corretamente que o preço da utilização de modelo é a eterna vigilância. É verdade também que se tais construções teóricas não seria absolutamente possível qualquer progresso nas ciências sócias (SHANIN, 1980, p.76).

A forma como constituem o modo como vivem reflete o que eles são, pois na comunidade a maioria dos camponeses trabalham com o cultivo do guaraná, outros com a mandioca, que torna sua base econômica, mesmo assim trabalham com outros produtos, para outros autores como Moura explicita que (1988): 
A COMERCIALIZAÇÃO DO GUARANÁ PELOS

CAMPONESES NA COMUNIDADE DIVINO

ESPÍRITO SANTO DO CASTANHAL

(BARREIRINHA/AM).

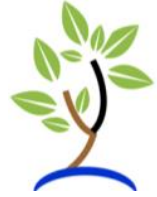

Ora, o conceito de camponês tem um peso que transcende a materialidade econômica da troca de mercadorias e sugere imediatamente características da sua organização social, tais como o trabalho familiar, os costumes de herança, a tradição religiosa e as formas de comportamento político. Não é chamando o camponês de pequeno produtor que se resolve o problema de sua permanência e transformação na sociedade capitalista. Do mesmo modo que não é se restringindo ao modo pelo qual os lavadores se autodesignamsitiantes, moradores, posseiros- que se resolvem as delicadas tramas das afinidades políticas entre esses subalternos (MOURA, 1988, p. 69 e 70).

É necessário entender como os camponeses estão organizados em sua unidade de produção, pois o modo como vivem é simples, mas que dependem muito do mercado e consórcio para vender o que produziram que para isto desenvolvem estratégias em sua unidade, no qual fazem o cultivo do guaraná, toda família ajuda, assim é na colheita, ou seja, existe ajuda mútua, porém quando a colheita é pouca somente a família ajuda. Em se tratando do termo camponês na Amazônia, alguns autores como Cruz (2007) que usa o termo camponês Ribeirinho e Witkoski (2010) que utiliza o termo camponês Amazônico, nesse sentido, Costa (2015) argumenta que:

Ambos aplicados no mesmo sentido, onde o camponês Ribeirinho e ou Amazônico é analisado na sua na sua polivalência, pois este campesinato se apropria dos ambientes "terra, água e floresta" para se reproduzir enquanto tal. Nesse sentido para esses autores a caracterização geral para compreensão da dinâmica camponesa considera o trabalho familiar um elemento central da produção camponesa, em que todos os membros família trabalham coletivamente, visando um objetivo comum. Especialmente na Amazônia a reprodução do campesinato requer uma combinação de atividades em que se realizam ao mesmo tempo diferentes tarefas como agricultura, pesca, extrativismo, artesanato, dentre outras (COSTA, 2015, p.3).

$\mathrm{Na}$ comunidade, os camponeses, desenvolvem diferentes atividades, agricultura, pesca, extrativismo, mas sua renda está concentrada na agricultura, onde fazem o cultivo. Cada família camponesa tem seu modo de trabalhar, uns trabalham manualmente no descascamento do guaraná, em outros é por meio da máquina de despolpar no qual o trabalho é em menos tempo, a jornada de trabalho de quem trabalha manualmente no descascamento é em torno de três horas. 


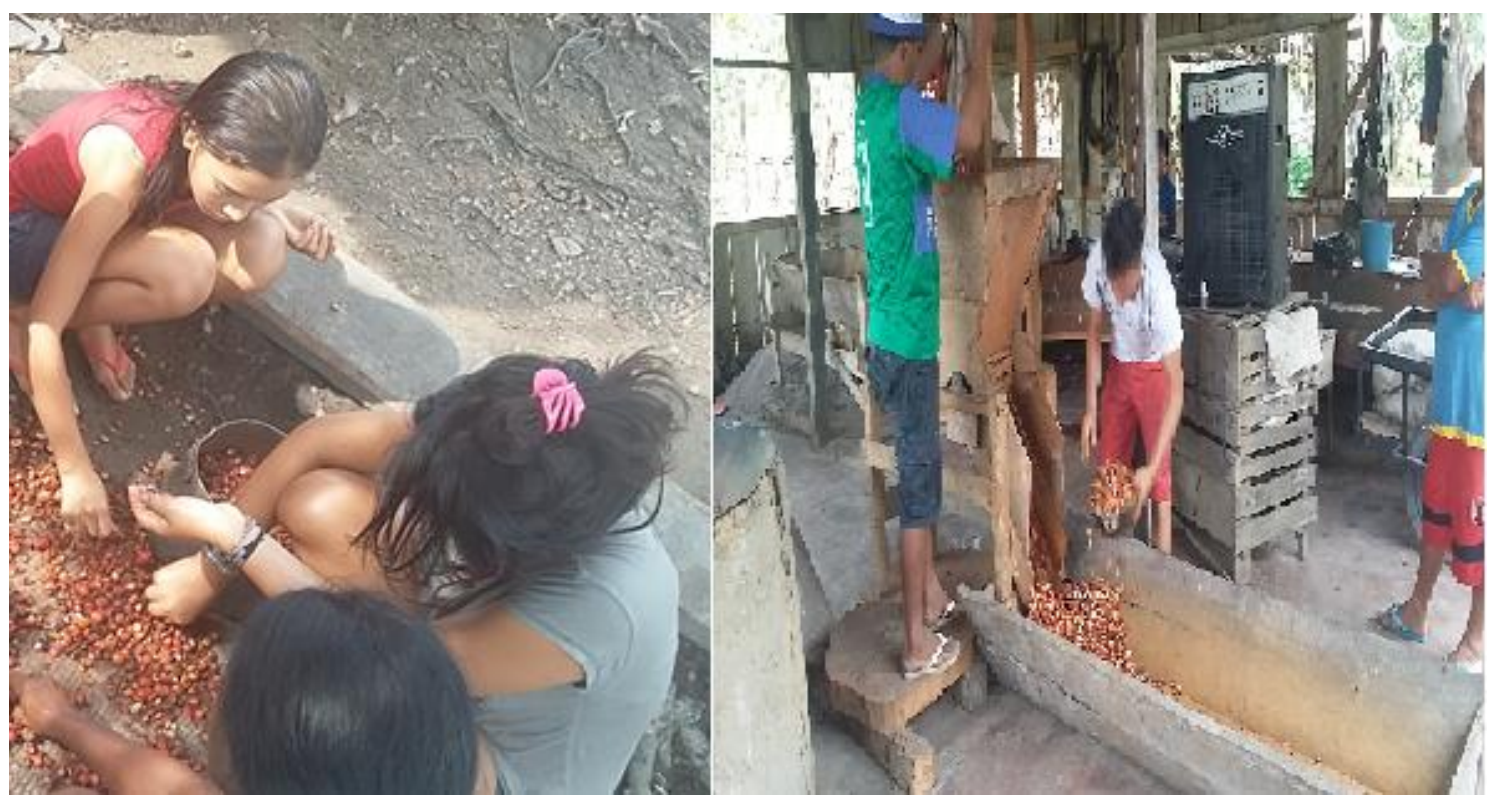

FIGURA 4 - 5: Unidade de produção, temos a família trabalhando manualmente com o guaraná, na figura (5) a presença de máquina, no qual facilita a força de trabalho.

Fonte: Trabalho de campo (22/12/2015).

Nesse caso toda a família contribui com sua força de trabalhado, e mesmo assim não diminui o tempo de trabalho comparado com outra família camponesa que possui meios para facilitar sua força de trabalho, pois até a força de trabalho tem um valor, nesse sentido afirma Marx (1982):

\begin{abstract}
Como de toda outra mercadoria, esse valor se determina pela quantidade de trabalho necessário para produzi - lá. A força de trabalho de homem consiste pura e simplesmente, na sua individualidade viva. Para poder crescer e manter-se um homem precisa consumir uma determinada quantidade de meio de subsistência, o homem como uma máquina se gasta e tem que ser substituída por outro homem. (MARX, 1982, p. 160).
\end{abstract}

Nesse sentido, cada membro da família é responsável por exercer diferentes especialidades, uns despolpam o guaraná, outros por colocar dentro da máquina, as mulheres geralmente ficam responsável pela torração do guaraná, pois somente um indivíduo não é capaz de realizar todo trabalho em menos tempo.

\title{
PRODUÇÃO FAMILIAR COMO PROCESSO ESTRATÉGICO DA MONOPOLIZAÇÃO PELO CAPITAL
}

$\mathrm{Na}$ unidade de produção familiar camponesa, os camponeses criam e recriam seu modo de vida, baseado no cultivo, pesca e extrativismo, possuindo dessa forma diversas atividades no seio de sua unidade. $O$ trabalho com o guaraná vem se destacando desde o ano de 2001, no qual poucos camponeses já trabalhavam com cultivo do guaraná, ou seja, foram se inserindo como associados do consócio Sataré Mawé, nesse sentido, para Silva (2015): 
A COMERCIALIZAÇÃO DO GUARANÁ PELOS

CAMPONESES NA COMUNIDADE DIVINO

ESPÍRITO SANTO DO CASTANHAL

(BARREIRINHA/AM).

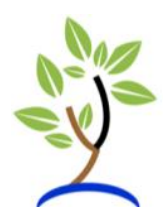

Na cidade de Parintins, trezentos Saterés fazem parte de um consócio que comercializam, além do guaraná, outros produtos como andiroba, copaíba, própolis, cestos de fibra, etc. A semente do guaraná é coletada pelos produtores indígenas do Baixo Amazonas. Depois de beneficiado, uma parte é comercializada em Manaus; a outra é exportada para França e Itália (SILVA, 2015, p.30).

Imagem dos camponeses no ato de comercialização:

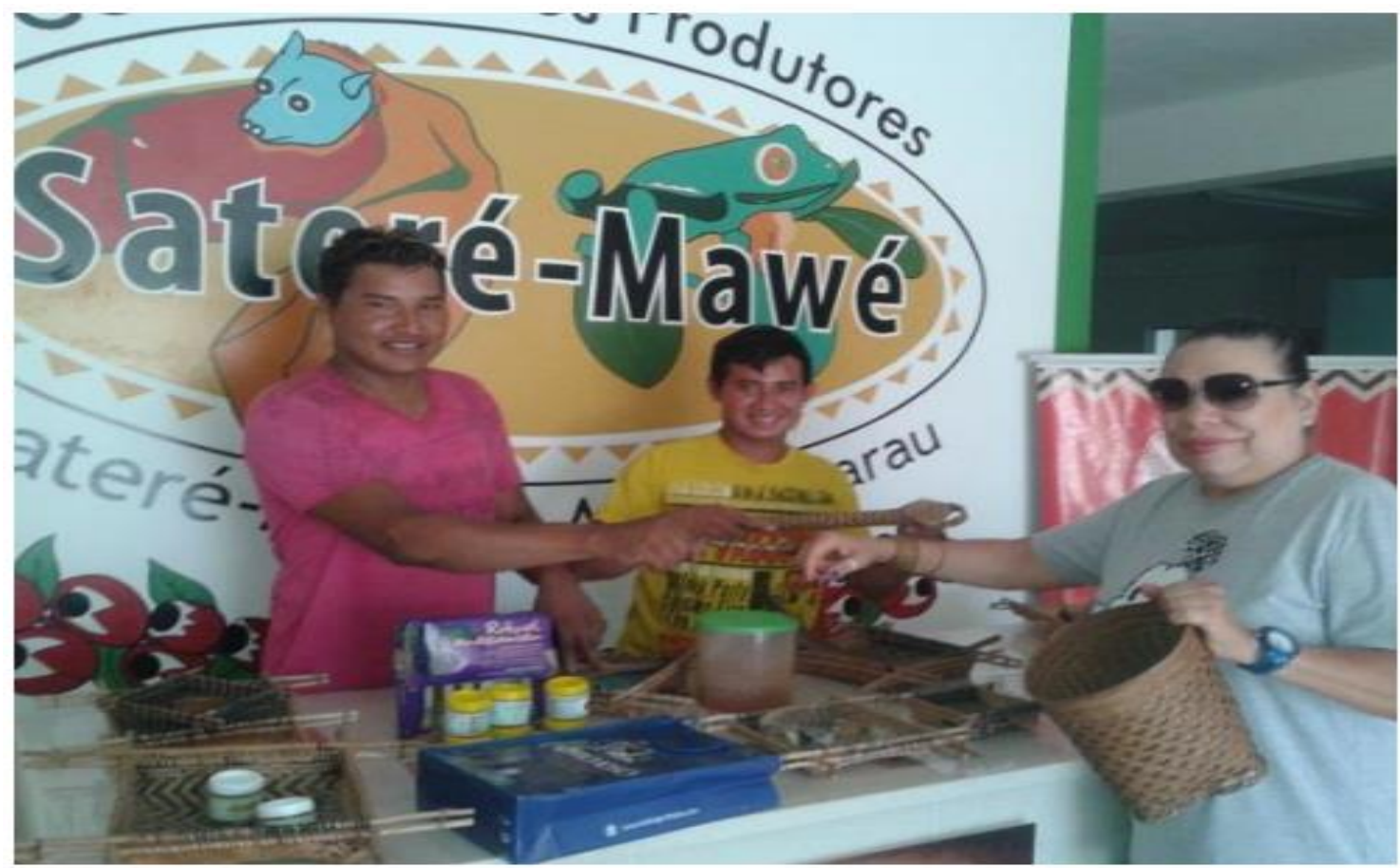

FIGURA - 6- Consórcio Sateré- Mawé em Parintins.

Fonte: Silva (2015).

Os camponeses da comunidade se territorializaram, desenvolvendo diversas atividades com a produção, que serve tanto para suprir suas necessidades como para a comercialização. Na comunidade, apenas o guaraná é comercializável, os demais (mandioca, banana, tucupi e dentre outros), os demais são utilizados para subsistência como para ser comercializado, quando é comercializado para o consócio, tem-se o processo da mais-valia, no caso do guaraná, os camponeses comercializam para o consócio o quilo por $R \$ 20,00$, antes comercializam para empresa regional localizada em Manaus, no qual os camponeses da comunidade comercializavam o quilo do guaraná por $R \$ 12,00$, depois quando o consórcio passou a territorializa-se na cidade de Parintins.

O consórcio é uma entidade autônoma auxiliar do Conselho Geral da Trigo SateréMawé (CGTSM), no ano de 2012, o Consórcio de produtores Sateré- Mawé (CPSM) depositou a marca Nusoken , para a comercialização em território nacional, e foi inaugurada em Parintins, o consórcio foi fundado como uma associação, ou seja, desde 2008 o consócio vem se fazendo presente na cidade de Parintins. Portanto, o 
A COMERCIALIZAÇÃO DO GUARANÁ PELOS

CAMPONESES NA COMUNIDADE DIVINO

ESPÍRITO SANTO DO CASTANHAL

(BARREIRINHA/AM).

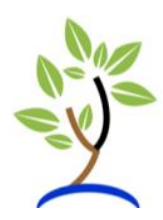

modo capitalista de produção não é o modo de produção de mercadoria, e sim, da mais valia, pois a mercadoria é essencial para o capital no qual pode se reproduzir Oliveira (2007):

Cabe esclarecer, neste momento, que o produto final do processo de produção não é mais-valia e sim a mercadoria. Essa mercadoria que sai do processo produtivo contém, aprisionada mais-valia. Numa palavra, é na produção que a mais-valia é gerada. Entretanto, a sua realização só se dá na circulação dessa mesma mercadoria. É pois, no momento da circulação que o capitalista converte a mercadoria em dinheiro, e, portanto apropria-se da mais-valia, que é trabalho social não pago (OLIVEIRA, 2007, p.20).

A família camponesa é essencial nesse processo, pois uma vez que as forças produtivas se unem tendem a se desenvolver, por isso que quanto mais forças produtivas há no seio da unidade de produção mais será a renda, e quanto mais o capital se apropria dessa mercadoria que foi comercializada pelos camponeses, mas desenvolve a mais-valia gerando o lucro, ou seja, o kg do guaraná que é materializado, e que é vendido por $R \$ 20,00$ pelo camponês é transformado em trabalho concreto, que logo o capital se apropria da força de trabalho, ou seja, o trabalho abstrato, que está contida na materialização da mercadoria, portanto o lucro é o próprio valor produzindo pelo capital, nesse sentido afirma Reis (2013).

\begin{abstract}
Com o processo de monopolização do território as empresas instaladas em áreas de acordo com seus interesses e monopolizam o território, determinando o que será produzido, estabelecendo contratos com os camponeses que passam a produzir e entregar sua produção aos interesses do capital, é nesse processo de monopolização que as empresas extraem a renda da terra (REIS, 2013, p. 2).
\end{abstract}

o camponês tem uma relação direta com o capital, porém os meios de produção do capital não se encontram no seio da unidade, pois na unidade a família camponesa busca em primeiro lugar satisfazer suas necessidades, e o capital somente se apropria da mercadoria quando se tem o valor de troca. Quando o camponês tem a relação com o consócio, na comercialização da produção se tem a subordinação da força de trabalho do camponês, que não é paga pelo valor total da mercadoria, ou seja, para o capital a mercadoria é valiosa, no qual se reproduz com outros valores, por isso não é paga pelo valor total, pois o que vai para a venda é o trabalho concreto. No caso do guaraná, os camponeses somente comercializam para o Consócio Sateré Mawé (CSM), que ao se territorializa-se monopoliza, nesse sentido Costa (2015):

\footnotetext{
É importante ao se falar do tema monopolização do capital se ater as transformações que este processo gera no espaço agrário brasileiro e mais especificamente na Amazônia. Faz-se necessário por este viés, entender a forma como o capital vem agindo diante das classes camponesas na região norte (COSTA, 2015, p.1407).
}

$\mathrm{Na}$ comunidade os camponeses sobrevivem da renda da produção, como a mandioca, quando um determinado produto não está na safra, outros substitui o que faz com que na unidade de produção os camponeses sempre estejam abastecendo para o mercado, que faz com que o campo rural ganhe relevância em sua produção, pois não é somente o que os camponeses produzem que devem ser bem visto pela sociedade, mais a maneira como expressam sua vida, em outro sentido é necessário que os 
A COMERCIALIZAÇÃO DO GUARANÁ PELOS

CAMPONESES NA COMUNIDADE DIVINO

ESPÍRITO SANTO DO CASTANHAL

(BARREIRINHA/AM).

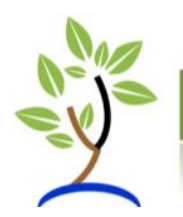

camponeses sempre estejam cultivando, o guaraná não é o único produto que os camponeses trabalham, como mencionado existem outros, por isso produção e consumo sempre se manifestam juntos, um depende do outro para está em equilíbrio, ou seja, a produção é imediatamente consumo, que ao colher o produto o camponês está suprindo suas necessidades, pois sabe que pode comercializar. Quando se trata de outros produtos que não necessariamente seja o guaraná, os camponeses comercializam diretamente para o consumidor final, em outro sentido, quando o camponês não consegue comercializar diretamente para o consumidor final, outros agentes se manifestam na circulação da mercadoria como (atravessador, feirantes), que fazem parte desse processo.

O trabalho com a terra simboliza vida, é a maneira que o camponês expressa sua vivência "assim, muitas vezes o camponês é para a sociedade um estranho, alguém que está fora de todo contexto do mundo, que não se adequa a nenhum tipo de classe, profissão, modo de vida, disseminado na atual sociedade" (SANTANA, 2012, p.12).

Para o camponês o trabalho com a terra representa muito mais que um simples cultivo, para eles, representa liberdade, que está relacionado como controlam o tempo de trabalho, eles decidem o horário que vão para o roçado, e a vinda do seu trabalho, seja na colheita, plantio, pesca, caça, geralmente saem para trabalhar pela parte da manhã, 6:00 horas, não por uma obrigação, mas pela relação de liberdade que eles mantêm com a terra. $O$ trabalho nos roçados é a principal atividade que desenvolvem, principalmente com o guaraná, que vem se tornando uma de suas principais atividades atualmente no município de Barreirinha.
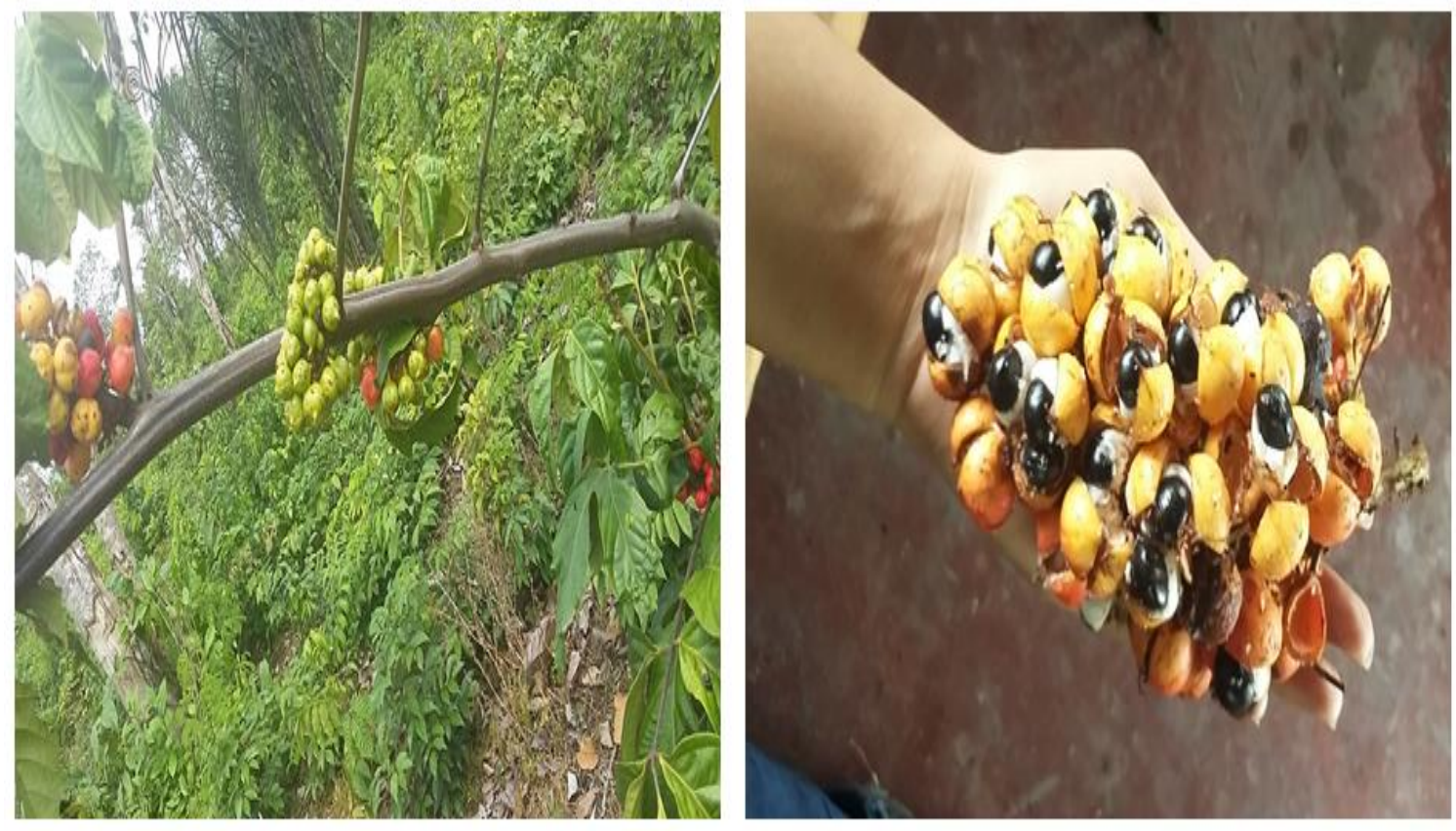

FIGURA 7 e 8: As sementes do guaraná são em ramas

Fonte: Trabalho de campo (22/12/2015).

Alguns camponeses ainda trabalham manualmente com o guaraná, outros são por meio de máquinas, e que facilita sua força de trabalho, porém, mesmo com as 
A COMERCIALIZAÇÃO DO GUARANÁ PELOS

CAMPONESES NA COMUNIDADE DIVINO

ESPÍRITO SANTO DO CASTANHAL

(BARREIRINHA/AM).

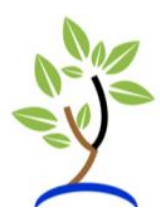

exigências da força de trabalho distinta, (manual e por máquinas), o preço do $\mathrm{kg}$ do guaraná vai ser o mesmo, pois o que interessa para o capital é o trabalho materializado e o lucro da mercadoria, que a partir de uma única mercadoria pode ser atribuído vários preço, ou seja, o capital se desenvolve por meio de suas próprias contradições, e o trabalho que o camponês exerce em sua unidade é o que importa para a aceleração do desenvolvimento do capital, pois na comunidade o camponês é um sujeito que trabalha tanto para suprir sua necessidade como para o capital, em outro sentido Paulino 2003:

\begin{abstract}
A recriação dos camponeses não ocorre como dádiva, tampouco como concessão do capital, mas como situação objetiva que combina uma serie se variáveis que culminam na energia de encontrarem saídas, sempre que necessário (PAULINO, 2003, p.160).
\end{abstract}

De primeira base os camponeses recorrem aos mercados, associações, cooperativas, consócios, para comercializar sua produção, no caso da comunidade, somente alguns deles são associados pelo consórcio, e pela própria associação da comunidade, não existem uma cooperativa direcionada para comercializar a produção dos camponeses, como mencionado o consórcio somente compra o guaraná, o restante da produção (mandioca, banana, laranja, cupuaçu e dentre outros) comercializam para o mercado da cidade de Parintins.

Assim, como os camponeses precisam se recriar em sua unidade, o capitalismo precisa gerar lucro, pois sua base primordial está na produção camponesa, pois o objetivo são duas lógicas distintas, de um lado a classe em busca de renda e outra em busca de lucro, sendo que o consócio está territorializado na cidade de Parintins, que faz com que o capital se desenvolva por meio das contradições, nesse sentido afirma Oliveira:

\begin{abstract}
O que esse processo contraditório de desenvolvimento capitalista no campo revela, é que, no primeiro caso, o capital territorializa-se. Estamos, portanto, diante do processo de territorialização do capital monopolista na agricultura. No segundo caso, esse processo contraditório revela que o capital monopoliza o território sem entretanto territorializa-se. Estamos, pois, diante do processo de monopolização (OLIVEIRA, 2001. p.24).
\end{abstract}

A monopolização do capital assegura a transferência da matéria prima para outros setores, o guaraná, é comercializado para Itália e França, no qual se dá a lógica contraditória do capital, e como mencionado se desenvolve pelo processo contraditório, o capital tem como a base primordial as forças de trabalho dos camponeses, no qual conseguem produzir a mercadoria para se desenvolver, ou seja, tanto os camponeses como os agentes institucionais têm uma relação de comercio.

É dessa maneira que manifestam a sua vida, que é por meio do seu modo de vida que adquirem habilidades, que está relacionado às especialidades que cada camponês desenvolve no seio da sua unidade, principalmente nos roçados, casas de farinhas e dentre outras atividades, ou seja, o camponês se submete primeiramente as exigências de suas próprias necessidades, (vendem para adquirir novas mercadorias) e em segundo ao capital, (comercializam para adquirir mais dinheiro). 
A COMERCIALIZAÇÃO DO GUARANÁ PELOS

CAMPONESES NA COMUNIDADE DIVINO

ESPÍRITO SANTO DO CASTANHAL

(BARREIRINHA/AM).

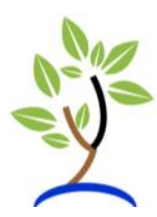

\section{CONCLUSÃO}

Os camponeses constituem seu modo de vida de acordo com sua necessidade, no qual trabalham com o cultivo, alguns produtos são bastante relevantes no mercado e no Consórcio dos Produtores Sateré-Mawé (CSM), tomamos como exemplo o guaraná e a mandioca, que é a base econômica da comunidade, mas os camponeses sobrevivem da pesca e de outros produtos que não necessariamente são comercializados para o mercado.

O guaraná vem se tornando uma potencialidade para o cultivo, no qual a maioria trabalha e realiza mutirão. Outra produção considerada a base econômica da comunidade é a mandioca, no qual comercializam somente para Parintins-AM, devido a facilidade no transporte e proximidade que tem da própria cidade e a comunidade.

Tudo que é produzido na unidade de produção camponesa tem uma finalidade, seja para própria comercialização e para subsistência e quando o produto não vai direto para sua subsistência como é o caso do guaraná, eles comercializam e a renda que extrai, podem comprar outras mercadorias que vai servir para suprir a necessidade da família camponesa.

O consócio sateré-mawé é o único que compra o guaraná da comunidade Divino Espírito Santo do Castanhal, embora muitas outras comunidades são associadas ao consórcio que também comercializam o guaraná que são fundamentais nesse processo.

Os camponeses estão constantemente envolvidos em atividades, seja na colheita, cultivo, criação, pois é desta maneira que demostram que são trabalhadores, ao contrário, não somente pelo que demostram que são trabalhadores, mas pelo fato de constituírem seu modo de vida, e é por meio de seu trabalho que conseguem se reproduzir.

\section{REFERÊNCIAS}

ARAUJO, E. S. Sobre as categorias valor e preço da força de trabalho em Marx. In: XIX Encontro Nacional de Economia Política, 2014, Florianópolis - SC. XIX Encontro Nacional de Economia Política - Anais, 2014.

COSTA, R.C; FERREIRA, B. E. S ; CECILIA, V. N. Mercado e biodiversidade. --Manaus: editora INPA, 2015. 101 p.:il, color.

COSTA, L; F. B.. CRUZ, M. J. M. Marques Oliveira Marques. A agricultura camponesa na Amazônia: um estudo de caso no assentamento de Vila Amazônia, Parintins-AM. In: XI ENAPEGE, 2015, Presidente Prudente. Anais do XI - ENAPEGE, 2015. v. 1. 
A COMERCIALIZAÇÃO DO GUARANÁ PELOS

CAMPONESES NA COMUNIDADE DIVINO

ESPÍRITO SANTO DO CASTANHAL

(BARREIRINHA/AM).

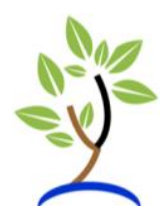

MARX, K. Para crítica da economia política: salário, preço e lucro. O rendimento e suas fontes. A economia vulgar. Tradução de Edigard Malogoliet al. São Paulo: Abril Cultura, 1982.

MARTINS, R. E.. Domesticação de plantas medicinais e aromática: caminhos. In: CONGRESSO BRASILEIRO DE OLERICULTURA. 53. Anais...Palmas: ABH. 2014.

MOURA, M. M.. Camponeses. 2. Ed. São Paulo: Ática, 1988.

OLIVEIRA, A. U. Agricultura Camponesa no Brasil. São Paulo, editora Contexto, 2001.

OLIVEIRA, A. U.. Modo de produção capitalista, Agricultura e Reforma Agrária. São Paulo: Labur Edições, 2007.

PAULINO, E. T.. Por uma geografia dos camponeses. Ed. UNESP, São Paulo, 2003.

PEREIRA, J. C. R. Pesquisa com guaranazeiro na Embrapa Amazônia Ocidental: status atual e perspectivas. Manaus: Embrapa Amazônia Ocidental, 2007.

PEREIRA, J. C. R. Terra e vida: a geografia dos camponeses no norte do Paraná. 2003. 430 f. Tese (doutorado) - Universidade Estadual Paulista, Faculdade de Ciências e Tecnologia, 2003.

REIS, L. C.. A sujeição da Renda da Terra e As repercussões no Campo: O contraste entre Petrolina-PE e Capela-SE. In: I Simpósio Baiano de Geografia Agrária e XI Semana de Geografia da UESB: O campo Baiano na relação Estado, Capital, Trabalho: Espaço de Contradições, Espaço de lutas, 2013, Vistoria da Conquista. Anais I Simpósio Baiano de Geografia, 2013. p. 1-20.

SANTANA, G. C. P. As diferentes formas de reprodução do campesinato no município de Itabaiana, SE. In: 3ํS Seminário Regional Norte e Nordeste de Pós Graduação em Geografia, 2012, João Pessoa. 3ํ SERNNE, 2012.

SILVA, D. Belém da. A presença do léxico indígena nas toadas do boi-bumbá de Parintis. Dissertação (Mestrado em Letras e Artes). Escola Superior de Artes e Turismo. Universidade do Estado do Amazonas. Manaus, 2015.

TRICAUD, S. ; PINTON, F.; PEREIRA, H. dos S.. . Saberes e práticas locais dos produtores de guaraná (Paullinia cupana Kunth var. sorbilis) do médio Amazonas: duas organizações locais frente à inovação. Boletim do Museu Paraense Emílio Goeldi. Ciências Humanas, v. 11, p. 33-53, 2016.

Submetido em: 21/08/2017 Aceito para publicação em: 13/02/2018 